\title{
EFICIÊNCIA TÉCNICA NA PRODUÇÃO DE LEITE EM PEQUENAS PROPRIEDADES DA MICRORREGIÃO DE VIÇOSA, MG ${ }^{1}$
}

\author{
Jerônimo Alves dos Santos ${ }^{2}$ \\ Wilson da Cruz Vieira ${ }^{3}$ \\ Antônio J. M. dos Santos Baptista
}

Resumo - Neste trabalho, avaliou-se a eficiência técnica em pequenas propriedades produtoras de leite da Microrregião de Viçosa, MG, assistidas no âmbito do convênio UFV/Nestlé (PDPL). Essas propriedades foram classificadas segundo o tamanho e o grau de sangue do rebanho, propondo medidas com vistas ao uso mais eficiente dos recursos produtivos. Utilizou-se um modelo de Análise Envoltória de Dados (DEA) para identificar as propriedades eficientes e ineficientes. Verificou-se que a maioria das propriedades, sob a pressuposição de retornos variáveis, foi eficiente, enquanto sob a pressuposição para retornos constantes, ineficiente. Observou-se que as propriedades, no período de 1999-2003, tornaram-se mais semelhantes, ou seja, evoluíram para padrões de maior eficiência técnica em seus processos produtivos.

Palavras-chave: DEA, eficiência técnica, produção de leite.

\section{Introdução}

O leite é tido como um alimento completo e indispensável à alimentação humana, pois nele existem substâncias que ajudam o combate a problemas como a osteoporose, além de proporcionar funções de complementação alimentar. Por ser uma fonte rica e acessível de nutrientes, vitaminas e cálcio, entre outros sais minerais, é grande o interesse econômico pelo leite.

${ }^{1}$ Artigo aceito para apresentação no $42^{\circ}$ Congresso Brasileiro de Economia e Sociologia Rural, realizado em Cuiabá, MT, no período de 25 a 28 de julho de 2004. Recebido 19/04/2004. Aceito em 01/06/2004.

${ }^{2}$ Estudante do Curso de Gestão do Agronegócio da Universidade Federal de Viçosa e Bolsista de Iniciação Científica do CNPq. E-mail: jeronimo2100@yahoo.com.br.

${ }^{3}$ Prof. Adjunto do Departamento de Economia Rural da Universidade Federal de Viçosa. CEP 36570-000 Viçosa, MG. E-mail: wvieira@ufv.br.

${ }^{4}$ Doutorando em Economia Aplicada do Departamento de Economia Rural da Universidade Federal de Viçosa. CEP 36570-000 Viçosa, MG. E-mail: tozecv@ yahoo.com. 
Segundo a EMBRAPA (2003), em 2002 os Estados Unidos produziram 75.025 mil toneladas de leite, o que corresponde a $15 \%$ da produção mundial, sendo esse país também o maior consumidor mundial deste produto. Na segunda posição está a Índia, que possui o maior rebanho bovino do mundo, tendo produzido, naquele ano, aproximadamente $7,0 \%$ da produção mundial. O Brasil, mesmo tendo o segundo maior rebanho bovino do mundo, detém o primeiro rebanho comercial, sendo o sexto maior produtor de leite do mundo e tendo produzido, em 2002, $23.260 \mathrm{mil}$ toneladas, ou seja, cerca de $4,7 \%$ da produção mundial.

De acordo com Carvalho et al. (2003), a produção brasileira de leite cresceu na década de 1990 a uma taxa anual de 4\%, superior à de todos os países que ocupam os primeiros lugares, respondendo por $66 \%$ do volume total de leite produzido nos países que compõem o Mercosul. Pelo faturamento de alguns produtos da indústria brasileira de alimentos nessa década, pôde-se avaliar a importância relativa do setor lácteo no contexto do agronegócio nacional, que registrou um aumento de $248 \%$ contra $78 \%$ de todos os outros segmentos.

Segundo Carvalho et al. (2003), a atividade leiteira, além de estar entre as seis mais importantes atividades da agropecuária brasileira, desempenha papel relevante no suprimento de alimentos e na geração de emprego e renda para a população do meio rural. Do valor bruto da agropecuária estimado em $\mathrm{R} \$ 103,5$ bilhões em 2002, aproximadamente $\mathrm{R} \$ 41$ bilhões são de produtos pecuários, sendo o leite um dos principais, com o valor de 6,6 bilhões de reais, ou seja, 16\% do valor bruto da produção pecuária nacional.

Na Figura 1, encontra-se ilustrada a evolução da produção de leite no período de 1990 a 2002. Observa-se, nessa figura, que houve aumento considerável na produção de leite, que passou de 14,5 bilhões de litros em 1990 para 23,26 bilhões em 2002, correspondendo a um crescimento de $60,41 \%$ nesse período. 


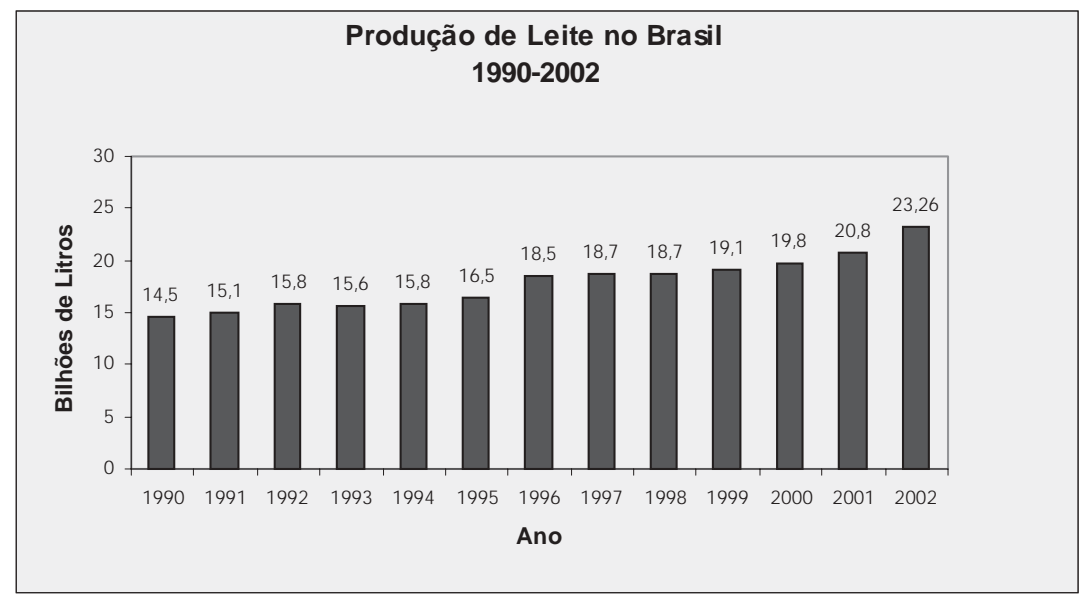

Fonte: Censo Agropecuário e Pesquisa da Pecuária Municipal (IBGE, 2003)

Figura 1- Produção de leite no Brasil no período de 1990 a 2002.

Mesmo o Brasil possuindo uma taxa de crescimento na produção de leite elevada, cerca de $4 \%$ ao ano, há discrepâncias em relação ao número de produtores e à quantidade produzida. Segundo Gomes (2000), a estrutura de produção de leite no Brasil caracteriza-se pelo fato de muitos produzirem poucos e poucos produzirem muito. Aqueles com até 50 litros de leite/dia correspondem a 50\% do número total de produtores, mas respondem por apenas $10 \%$ da produção. No outro extremo, os produtores com mais de 200 litros de leite/dia correspondem a apenas $10 \%$ do número total de produtores, porém respondem com $50 \%$ da produção nacional.

O Estado de Minas Gerais é o maior produtor de leite do país, com um rebanho leiteiro de aproximadamente 6,5 mil cabeças, com produção de 5.981 bilhões de litros em 2001, representando cerca de 29,2\% de todo o leite do país. As mesorregiões que mais colaboram com a produção de leite em Minas Gerais são, em primeiro lugar, o Triângulo Mineiro/Alto Paranaíba, com aproximadamente 1,37 bilhão de litros de leite em 2001, seguido por Sul/Sudoeste de Minas, Central Mineira, Oeste de Minas e Zona da Mata, que ocupou o quinto lugar entre as mesorregiões produto- 
ras de leite, com uma produção de, aproximadamente, 586 milhões de litros, além de ser umas das mais importantes e tradicionais mesorregiões produtoras de leite do estado (EMBRAPA, 2003).

Entre as microrregiões da Zona da Mata mineira, a de Juiz de Fora é a primeira em produção, com aproximadamente 158 milhões de litros de leite em 2001; em seguida está a microrregião de Cataguases e Muriaé, em sexto lugar, e, na penúltima colocação, vem a Microrregião de Viçosa, com uma produção de aproximadamente 46,7 milhões de litros de leite em 2001, além de possuir umas das menores produtividades por vaca ordenhada das microrregiões, com uma produtividade por vaca de 1.230 litros/vaca/ano contra 1.756 litros/vaca/ano de Cataguases (EMBRAPA, 2003).

Visando melhorar esse quadro, na Microrregião de Viçosa têm sido tomadas algumas medidas com os produtores de leite, visando facilitar o acesso à tecnologia. Cita-se, como exemplo, o Programa de Desenvolvimento da Pecuária Leiteira da Microrregião de Viçosa (PDPL). Esse Programa é uma iniciativa da Universidade Federal de Viçosa e da Nestlé, que estabeleceram um convênio, tendo como executora a Fundação Artur Bernardes (FUNARBE). A parte operacional desse Programa teve início em outubro de 1988.

O PDPL tem como objetivos incentivar a especialização nas propriedades produtoras de leite; melhorar as práticas de manejo, alimentação e higiene do rebanho; melhorar a infra-estrutura de produção; e dinamizar a administração, além de proporcionar treinamento especializado aos estudantes de graduação da UFV, nas áreas de zootecnia, veterinária e agronomia, entre outras. O Programa está construindo as bases para aquelas propriedades que antes estavam em desvantagem na produção e concorrência e, hoje, vêm tendo melhor desempenho no mercado, podendo competir de forma mais eficiente.

Este trabalho objetivou, em geral, avaliar a eficiência técnica nas pequenas propriedades produtoras de leite da Microrregião de Viçosa, MG, assistidas no âmbito do convênio UFV/Nestlé, no período de novembro 
de 1999 a outubro de 2003.

Os objetivos específicos foram:

a) Classificar as pequenas propriedades de leite da Microrregião de Viçosa, segundo o tamanho e o grau de sangue do rebanho.

b) Utilizar um modelo de Análise Envoltória de Dados (DEA) para identificar as propriedades mais eficientes tecnicamente dos últimos quatro anos.

c) Propor medidas visando ao uso mais eficiente dos recursos nas propriedades analisadas.

\section{Referencial teórico}

Um produtor, quando utiliza insumos para transformá-los em produtos, está sujeito a várias restrições, como a econômica, financeira etc. Além dessas, existe outra importante e que se caracteriza como uma restrição técnica: a função de produção.

A função de produção identifica a forma para solucionar os problemas técnicos da produção, por meio da mostra da combinação de fatores que podem ser utilizados no processo produtivo (Carvalho, 1984). Ela indica o máximo de produto que se pode obter com as quantidades de fatores, uma vez escolhido o processo de produção mais conveniente.

Segundo Carvalho (1984), normalmente na análise microeconômica, representa-se a função de produção da seguinte forma: $\mathrm{y}=\mathrm{f}\left(\mathrm{x}_{1}, \mathrm{x}_{2}, \ldots, \mathrm{x}_{\mathrm{n}}\right)$, em que y é a quantidade produzida do bem e $\mathrm{x}_{1}, \mathrm{x}_{2}, \ldots, \mathrm{x}_{\mathrm{n}}$ identificam as quantidades utilizadas de diversos fatores, respeitando-se o processo de produção mais eficiente escolhido. A função de produção é sempre definida no tempo e para níveis não-negativos dos fatores e do produto, ou seja, $y \geq 0, x \geq 0$. 
No curto prazo, a função de produção é definida considerando-se insumos variáveis e fixos (independentes do nível de produção). No caso mais simples, têm-se dois insumos: um insumo variável e outro fixo. Nesse caso, a quantidade produzida para que possa variar a produção dependerá da quantidade do insumo variável.

Em relação ao longo prazo, todos os insumos variam dependendo do nível de produção. No caso mais simples, trabalhando com dois insumos, pode-se ter uma isoquanta, em que se produz a mesma quantidade com diferentes combinações desses insumos (Carvalho, 1984). Através das relações existentes na tecnologia de produção entre os insumos e os produtos, é possível analisar a eficiência de determinada firma.

A eficiência técnica requer que se utilize um processo de produção que não use mais insumos do que o necessário para dado produto, enquanto a eficiência alocativa reflete a habilidade da firma em utilizar os insumos em proporções ótimas. E, por último, a eficiência econômica refere-se à capacidade dos produtores em conduzir o processo produtivo, com vistas a obter o mínimo de custo ou o máximo de lucro.

Caso a firma não trabalhe de maneira eficiente, haverá desperdício de fatores de produção, e ela não será capaz de maximizar seu lucro; sua capacidade de se manter no mercado de maneira competitiva será cada vez mais difícil.

\section{Metodologia}

\section{Modelo analítico}

A produção de leite envolve sistemas de produção que, de acordo com o conjunto de variáveis consideradas [insumos $\left(\mathrm{x}_{1}, \mathrm{x}_{2}, \ldots, \mathrm{x}_{\mathrm{n}}\right.$.) e produtos $\left.\left(\mathrm{y}_{1}, \mathrm{y}_{2}, \ldots, \mathrm{y}_{\mathrm{n}}\right)\right]$, fica mais complexa a alocação de recursos. Neste trabalho foi utilizado o método de fronteira de produção na análise da eficiência técnica nas pequenas propriedades produtoras de leite da 
Microrregião de Viçosa, MG.

A fronteira de produção é a máxima quantidade de produtos que podem ser obtidos dados os insumos utilizados (Lins e Meza, 2000). Neste trabalho, a determinação de fronteira eficiente foi feita mediante o método Data Envelopment Analysis (DEA). A DEA, ou análise envoltória de dados, segundo Gomes (1999) é uma abordagem não-paramétrica de programação matemática, como alternativa para os métodos estatísticos convencionais para estimação de eficiência relativa de unidades produtivas. Sua mais importante característica é a habilidade em manipular, efetivamente, a natureza multidimensional de insumos e produtos nos processos de produção.

A DEA consiste em encontrar a melhor firma virtual a partir de um conjunto de firmas de uma amostra. Caso a firma virtual seja melhor do que qualquer firma da amostra, ou por produzir mais com a mesma quantidade de insumos ou por produzir a mesma quantidade com menos insumos, a firma analisada será ineficiente. Define-se DMU (Decision Making Unit), como firma, departamento, propriedade rural ou unidade administrativa cuja eficiência está sendo analisada. O conjunto de DMUs utilizadas em uma DEA deve ter em comum a utilização dos mesmos insumos e produtos e, também, ser homogêneo e ter autonomia na tomada de decisões (Lins e Meza, 2000).

Com relação às variáveis consideradas [insumos $\left(\mathrm{x}_{1}, \mathrm{x}_{2}, \ldots, \mathrm{x}_{\mathrm{n}}\right.$. $)$ e produtos $\left.\left(\mathrm{y}_{1}, \mathrm{y}_{2}, \ldots, \mathrm{y}_{\mathrm{n}}\right)\right]$, cada uma delas deve operar na mesma unidade de medida em todas as DMUs, mas pode estar em unidades diferentes das outras (Lins e Meza, 2000). Utilizando os conceitos de fronteira de produção da DEA aplicados às DMUs, pode-se formular um modelo, como o proposto por Charnes et al. (1978). Este modelo ficou conhecido como CCR, em razão das iniciais dos nomes dos autores, sendo também conhecido como CRS (Constant Returns to Scale) e possuindo orientação insumo ou orientação produto, conforme descrito nos parágrafos subseqüentes. 
Considera-se que $n$ DMUs e cada uma delas utilizam $\mathrm{k}$ insumos e produzem m produtos. São construídas duas matrizes: a matriz $\mathrm{X}$ de insumos, de dimensões ( $\mathrm{k} \times \mathrm{n}$ ) e a matriz Y de produtos, de dimensões ( $\mathrm{m} \times \mathrm{n}$ ), representando os dados de todas as n DMUs.

$$
X=\left(\begin{array}{cccc}
x_{11} & x_{12} & \cdots & x_{1 n} \\
x_{21} & x_{22} & \cdots & x_{2 n} \\
\vdots & \cdots & & \vdots \\
x_{k 1} & x_{k 2} & \cdots & x_{k n}
\end{array}\right) \quad Y=\left(\begin{array}{cccc}
y_{11} & y_{12} & \cdots & y_{1 n} \\
y_{21} & y_{22} & \cdots & y_{2 n} \\
\vdots & \cdots & \vdots \\
y_{m 1} & y_{m 2} & \cdots & y_{m n}
\end{array}\right)
$$

Na matriz X, cada linha representa um insumo e cada coluna, uma DMU. Na matriz Y, cada linha indica um produto e cada coluna, uma DMU.

Alves (1999) salientou que a matriz X deve satisfazer as seguintes condições:

$$
\begin{aligned}
& \sum_{i=1}^{k} \mathrm{x}_{\mathrm{ij}}>0 \\
& \sum_{j=1}^{n} \mathrm{x}_{\mathrm{ij}}>0 \\
& \mathrm{x}_{\mathrm{ij}} \geq 0 ; \forall{ }_{\mathrm{ij}}
\end{aligned}
$$

Isso significa que os níveis de uso de insumos são não-negativos e cada linha e cada coluna contêm, pelo menos, um nível de insumo positivo, isto é, cada DMU consome ao menos um insumo, e uma DMU, pelo menos, consome o insumo que está em cada linha. 
De forma semelhante, a matriz Y satisfaz as seguintes condições:

$$
\begin{aligned}
& \sum_{i=1}^{m} y_{i j}>0 \\
& \sum_{j=1}^{m} y_{i j}>0 \\
& y_{i j} \geq 0, \forall_{i j}
\end{aligned}
$$

Isso significa que os níveis de produção são não-negativos, ou seja, cada produto é produzido por uma DMU, pelo menos, e cada DMU produz pelo menos um produto. Assim, para a i-ésima DMU são representados os vetores e para insumo e produto, respectivamente.

Para cada DMU, pode-se obter uma medida de eficiência, que é a razão entre todos os produtos e todos os insumos. Para i-ésima DMU, tem-se a seguinte medida de eficiência:

$$
\mathrm{i}=\frac{\mathrm{u}^{\prime} \mathrm{y}_{\mathrm{i}}}{\mathrm{v}^{\prime} \mathrm{x}_{\mathrm{i}}}=\frac{\left(\mathrm{u}_{\mathrm{i}} \mathrm{y}_{1 \mathrm{i}}+\ldots+\mathrm{u}_{\mathrm{m}} \mathrm{y}_{\mathrm{mi}}\right)}{\left(\mathrm{v}_{\mathrm{i}} \mathrm{x}_{1 \mathrm{i}}+\ldots+\mathrm{u}_{\mathrm{k}} \mathrm{x}_{\mathrm{ki}}\right)}
$$

em que u é um vetor ( $\mathrm{m}$ x 1) de pesos nos produtos e v, um vetor de pesos nos insumos.

Segundo Gomes (1999), para selecionar os pesos ótimos para cada DMU especifica-se um problema de programação matemática. Para a i-ésima DMU, tem-se:

$\operatorname{Max}_{u, v}\left(\frac{\mathrm{u}^{`} \mathrm{y}_{\mathrm{i}}}{\mathrm{v}^{\prime} \mathrm{x}_{\mathrm{i}}}\right)$

sujeito a $:\left(\frac{\mathrm{u}^{`} \mathrm{y}_{\mathrm{J}}}{\mathrm{v}^{\prime} \mathrm{x}_{\mathrm{J}}}\right) \leq 1, \mathrm{j}=1,2, \ldots, \mathrm{n}$.

$\mathrm{u}, \mathrm{v} \geq 0$ 
Essa formulação envolve a obtenção de valores para u e v, de tal forma que a medida de eficiência para a i-ésima DMU seja maximizada, sujeita à restrição de que as medidas de eficiência de todas as DMUs sejam inferiores ou iguais a 1. Segundo Moita (1995), a característica-chave deste modelo é que os pesos u e v são tratados como incógnitas, sendo escolhidos de maneira que a eficiência da i-ésima DMU seja maximizada.

O modelo pode ser linearizado, tornando possível sua solução por meio de métodos de programação linear convencionais. A formulação linearizada é a seguinte:

$\operatorname{Max}_{u, v}\left(\mathrm{u}^{\prime} \mathrm{y}_{\mathrm{i}}\right)$

sujeito a :

$\mathrm{vx}_{\mathrm{i}}=1$

$u^{\prime} y_{j}-v^{\prime} x_{j} \leq 0, j=1,2, \ldots, n$

$\mathrm{u}, \mathrm{v} \geq 0$

Na análise do DEA, o modelo linear deve ser aplicado a cada DMU, a fim de obter, uma a uma, as medidas de eficiência. Entretanto, como a maioria das restrições é a mesma para cada problema, a obtenção da solução torna-se simples. Caso a eficiência obtida para a DMU que esteja sendo testada seja igual a 1, ela é eficiente em relação às demais; caso contrário, é ineficiente.

Pela dualidade em programação linear, pode-se chegar a um modelo dual da formulação linearizada da seguinte forma:

$\operatorname{MIN}_{\theta, \lambda} \theta$

sujeito a:

$-\mathrm{y}_{\mathrm{i}}+\mathrm{Y} \geq 0$

$\theta \mathrm{x}_{\mathrm{i}}-\mathrm{X} \lambda \geq 0$

$\lambda \geq 0$ 
em que é um escalar (escore de eficiência da orientação insumo), cujo valor é a medida de eficiência da i-ésima DMU. Se for igual a 1, a DMU será eficiente; caso contrário, é ineficiente. O é um vetor ( n x 1), cujos valores são calculados de maneira que se obtenha a solução ótima. Para uma propriedade eficiente, os valores de são iguais a zero; para uma propriedade ineficiente, indica os pesos das propriedades que são benchmarks (Gomes, 1999).

Para o cálculo da eficiência das DMUs, pode-se utilizar também o modelo chamado de BCC (retornos variáveis), em que se adiciona uma restrição ao modelo $\mathrm{CCR}$ (retorno constante à escala). É importante apresentar o modelo BCC junto com o modelo CCR para que se determine a eficiência de escala. $\mathrm{O}$ modelo $\mathrm{BCC}$ pode ser representado da seguinte forma:

$\operatorname{MIN}_{\theta, \lambda} \theta$

sujeito a:

$-\mathrm{y}_{\mathrm{i}}+\mathrm{Y} \geq 0$

$\theta \mathrm{x}_{\mathrm{i}}-\mathrm{X} \lambda \geq 0$

$\mathrm{N} 1 \lambda=1$

$\lambda \geq 0$

em que N1 é um vetor ( $\mathrm{n} \times 1$ ) de números uns, sendo as demais variáveis já definidas anteriormente.

Para que seja possível determinar os retornos crescentes e decrescentes à escala, é necessário apresentar o modelo BCC junto com o modelo CCR; o modelo BCC não- crescente pode ser representado da seguinte forma:

$\mathrm{MIN}_{\theta, \lambda} \theta$ 
sujeito a:

$-\mathrm{y}_{\mathrm{i}}+\mathrm{Y} \geq 0$

$\theta \mathrm{x}_{\mathrm{i}}-\mathrm{X} \lambda \geq 0$

$\mathrm{N} 1 \lambda \leq 1$

$\lambda \geq 0$

em que todas as variáveis já foram definidas anteriormente.

Analisando os dois modelos CCR e o BCC, podem-se definir as eficiências das firmas. Para eficiência de escala, o CCR tem que ser igual ao BCC ( $\mathrm{CCR}=\mathrm{BCC}$ ); caso não sejam iguais, a DMU é ineficiente; nesse caso, têm-se mais duas análises: se CCR é igual ao BCC não-crescente, têm-se retornos crescentes; e se CCR for diferente de BCC não-crescentes, têm-se retornos decrescentes.

\section{Fonte de dados e procedimentos utilizados}

Os dados utilizados neste trabalho foram obtidos do Programa de Desenvolvimento da Pecuária Leiteira da Microrregião de Viçosa (PDPL) das propriedades produtoras de leite assistidas pelo convênio UFV/Nestlé. Para cada propriedade foram considerados: a quantidade anual de leite produzida (mil litros), o número total de vacas (lactação e secas), a área efetiva da propriedade dedicada à produção de leite (hectares) e o custo operacional efetivo (C.O.E) ${ }^{5}$, sendo este calculado com dados de final de período. Neste trabalho, a margem bruta é o resultado econômico da subtração do custo operacional efetivo da renda bruta. Foram considerados três tipos de tecnologia: alto (para as propriedades que possuem tanque de resfriamento e ordenhadeira); médio (para as propriedades que possuem taque de resfriamento ou ordenhadeira) e baixo (para as propriedades que não possuem tanque de resfriamento e nem ordenhadeira). Em relação ao grau de sangue do rebanho foram consi-

\footnotetext{
${ }^{5}$ O Custo Operacional Efetivo (COE) é o custo de produção sem incluir os custos com mão-de-obra familiar, depreciação do capital e custo de oportunidade.
} 
deradas as seguintes categorias: puro (15/16 HZ para cima), intermediário (entre 3/4 e 15/16 HZ) e mestiço (3/4 HZ para baixo).

Foram consideradas, primeiramente, as propriedades cujos produtores permaneceram no convênio no período de novembro de 1999 a outubro de 2002 (um total de 17 produtores). Posteriormente, foram considerados os produtores que permaneceram no convênio no período de novembro de 1999 a outubro de 2003 (um total de 11 produtores). Essa divisão das propriedades para três a quatro anos se deu por causa de alguns produtores que estavam por mais de três anos no PDPL terem desistido da pecuária de leite e vendido suas terras e também pelo fato de alguns deles terem sido dispensados por não estarem cumprindo as normas do convênio.

Para a correção do custo operacional efetivo total das propriedades, foi utilizado o IGP-DI da Fundação Getúlio Vargas (FGV), adotando-se, como base, outubro de 2003. Os modelos CCR (retornos constante à escala), BCC (retornos variáveis à escala) e o BCC não-crescente foram utilizados para medir a eficiência das propriedades e avaliar se elas estavam operando com eficiência de escala, retornos crescentes ou decrescentes. Utilizou-se o software $\mathrm{EMS}^{6}$ para calcular os escores de eficiência.

\section{Resultado e discussão}

\section{Classificação das propriedades produtoras de leite da microrregião de Viçosa, MG}

Os produtores de leite que participam do PDPL estavam dispersos na Microrregião de Viçosa em um raio de $50 \mathrm{~km}$. Dos 17 produtores participantes do convênio no período de novembro de 1999 a outubro de 2002, 29,41\% (5 produtores) localizavam-se no município de Paula Cândido, sendo este o município com o maior número de propriedades conveniadas. Os municípios de Cajuri, Araponga, Viçosa, São Miguel e Teixeiras contavam, cada um, com 5,88\% dos produtores, ou seja, apenas um. Das 17 propriedades, 10 possuíam alto nível tecnológico (para

${ }^{6} \mathrm{O}$ software SEM é gratuito e pode ser obtido no site http://www.wiso.unidortmund.de/lsfg/or/scheel/sem 
as propriedades que possuíam tanque de resfriamento e ordenhadeira), cinco nível médio e duas nível tecnológico baixo (para as propriedades que não possuíam tanque de resfriamento e nem ordenhadeira). Em relação ao grau de sangue, oito propriedades possuíam mais da metade dos animais com grau de sangue puro.

De acordo com a Tabela 1, a área total média das 17 propriedades, referente ao período de novembro de 1999 a outubro de 2002, era de 91,38 ha, aproximadamente, e, desse total, eram destinados, em média, 62,25\% à pecuária leiteira, ou seja, 56,88 ha; o número de vacas em lactação nas propriedades variou entre 2 e 60 . Oito produtores (47,05\% do total) tiveram entre 17 e 30 vacas em lactação. Em média, as vacas secas representavam $30,34 \%$ do total de vacas dos produtores conveniados.

Tabela 1- Média da área e do número de vacas do total das 17 propriedades, convênio UFV/Nestlé, no período de nov./99 a out./02

\begin{tabular}{|l|c|c|c|c|c|}
\hline Períodos & $\begin{array}{c}\text { Área total hec } \\
\text { (média) }\end{array}$ & $\begin{array}{c}\text { Área para } \\
\text { pecuária/hec } \\
\text { (média) }\end{array}$ & $\begin{array}{c}\text { total de } \\
\text { Vacas } \\
\text { (média) }\end{array}$ & $\begin{array}{c}\text { Vacas em } \\
\text { lactação } \\
\text { (média) }\end{array}$ & $\begin{array}{c}\text { Vacas } \\
\text { secas } \\
\text { (média) }\end{array}$ \\
\hline $1999-2000$ & 91,72 & 55,53 & 34 & 22 & 12 \\
\hline $2000-2001$ & 91,52 & 55,88 & 37 & 26 & 12 \\
\hline $2001-2002$ & 90,91 & 59,24 & 41 & 30 & 11 \\
\hline média & 91,38 & 56,88 & 37 & 26 & 11 \\
\hline
\end{tabular}

Fonte: PDPL - Convênio UFV/Nestlé (elaboração dos autores).

Observou-se, no período de 1999-2002, que quatro propriedades analisadas duplicaram suas produtividades. Também, verificou-se que seis propriedades duplicaram seus custos operacionais efetivos e duas propriedades tiveram suas margens brutas negativas, ressaltando-se que três propriedades aumentaram consideravelmente suas áreas para pecuária.

Das 11 propriedades participantes do convênio no período de novembro de 1999 a outubro de 2003, a maioria se localizava no município de Coimbra (4 produtores); os municípios de Cajuri, Viçosa e Araponga contavam, 
cada um, com 9,09\% dos produtores, ou seja, apenas um, e o município de Paula Cândido não teve nenhum produtor nesta análise.

Dessas propriedades, oito possuíam alto nível tecnológico, duas nível médio e uma nível tecnológico baixo. Em relação ao grau de sangue, sete propriedades possuíam mais da metade dos animais com grau de sangue puro.

De acordo com a Tabela 2, a média total das 11 propriedades do convênio foi de 93,24 ha, aproximadamente, e, deste total, foram destinadas, em média, 63,79\% à pecuária leiteira, ou seja, 59,49 ha. O número de vacas em lactação variou entre 13 e 60 . Em média, quatro produtores (36,36\% do total de 11 produtores) tiveram entre 15 e 25 vacas em lactação. As vacas secas representavam, em média, 26,35\% do total de vacas dos produtores conveniados.

Tabela 2- Média da área e do número de vacas do total das 11 propriedades, convênio UFV/Nestlé, no período de nov./99 a out./03

\begin{tabular}{|c|c|c|c|c|c|}
\hline Períodos & $\begin{array}{c}\text { Área total } \\
\text { ha } \\
\text { (média) }\end{array}$ & $\begin{array}{c}\text { Área para } \\
\text { pecuária/ha } \\
\text { (média) }\end{array}$ & $\begin{array}{c}\text { Total de } \\
\text { vacas } \\
\text { (média) }\end{array}$ & $\begin{array}{c}\text { Vacas em } \\
\text { lactação } \\
\text { (média) }\end{array}$ & $\begin{array}{c}\text { Vacas } \\
\text { secas } \\
\text { (média) }\end{array}$ \\
\hline $1999-2000$ & 95,95 & 54,15 & 37 & 25 & 12 \\
\hline $2000-2001$ & 95,92 & 54,23 & 41 & 29 & 13 \\
\hline $2001-2002$ & 98,08 & 59,37 & 46 & 35 & 11 \\
\hline $2002-2003$ & 83,02 & 70,20 & 47 & 37 & 10 \\
\hline média & 93,24 & 59,49 & 32 & 32 & 11 \\
\hline
\end{tabular}

Fonte: PDPL - Convênio UFV/Nestlé (elaboração dos autores).

Das propriedades avaliadas no período de nov./99 a out./03 houve duas que duplicaram suas produtividades, oito duplicaram seus custos operacionais efetivos e apenas uma teve sua margem bruta negativa, ressaltando-se que quatro propriedades aumentaram suas áreas para pecuária, consideravelmente. 
Observou-se, portanto, que, em média, os produtores conveniados ao PDPL usavam mais da metade de suas terras para a pecuária leiteira e mais de dois terço das vacas estavam em lactação.

\section{Análise da eficiência técnica das propriedades}

\section{Período de novembro/99 a outubro/2002 (17 propriedades)}

A média de eficiência das 17 propriedades, sob a pressuposição de retornos constantes à escala, no período de 1999-2000, de acordo com a Tabela 1A (Anexo), foi de $80,70 \%$, ou seja, elas poderiam reduzir suas quantidades de insumos em até $19,30 \%$ e produzir a mesma quantidade de leite ou, de forma alternativa, aumentar suas produções sem usar mais insumos. Nesse período, o menor escore de eficiência foi de 35,30\%, sendo encontradas cinco propriedades $(29,41 \%$ das 17$)$ eficientes, ou seja, com escore de eficiência $\theta$ igual a $100 \%$. Sob a pressuposição de retornos variáveis, a média, nesse período, foi de $86,32 \%$, ou seja, os produtores, em geral, puderam diminuir suas quantidades de insumos em $13,68 \%$ e permanecer produzindo a mesma quantidade de leite ou permanecer com as mesmas quantidades de insumos e aumentar sua produção sem utilizar mais insumos; o menor escore de eficiência foi de $36,44 \%$, sendo ainda encontradas oito propriedades eficientes, ou seja, $47,05 \%$. Quando se analisam eficiência de escala, retorno crescente e retorno decrescente, têm-se, respectivamente, 29,41; 52,94; e 17,65\% das propriedades, ou seja, cinco trabalharam com eficiência de escala, nove com retornos crescentes e três com retornos decrescentes.

Sob a pressuposição de retornos constantes à escala no período de 2000 2001, conforme a Tabela 2A (Anexo), a média de eficiência foi de 84,86\%, ou seja, os produtores poderiam reduzir suas quantidades de insumos em até $15,14 \%$ e produzir a mesma quantidade de leite ou, de forma alternativa, aumentar sua produção sem usar mais insumos; nesse período, o menor escore de eficiência foi de 44,54\%, sendo encontradas cinco propriedades eficientes, ou seja, 29,41\%. Na pressuposição de retornos va- 
riáveis, a média desse período foi de $95,85 \%$ e o menor escore de eficiência, de $68,08 \%$, sendo ainda encontradas 12 propriedades eficientes, ou seja, 70,59\%. Analisando a eficiência de escala, retorno crescente e retorno decrescente, obtiveram-se, respectivamente, 29,40; 35,30; e $35,30 \%$ das propriedades, ou seja, cinco trabalharam com eficiência de escala, seis com retornos crescentes e seis com retornos decrescentes.

No período de 2001-2002, sob a pressuposição de retornos constantes à escala, conforme a Tabela 3A (Anexo), a média de eficiência foi de 84,06\%; nesse período, o menor escore de eficiência foi de 62,21\%, além de terem sido encontradas quatro propriedades eficientes, ou seja, 23,53\%. Na pressuposição de retornos variáveis, a média, desse período foi de $93,93 \%$, ou seja, os produtores em geral poderiam reduzir suas quantidades de insumos em 6,07\% e permanecer produzindo a mesma quantidade de leite ou permanecer com a mesma quantidade de insumo e aumentar sua produção sem utilizar mais insumos; o menor escore de eficiência foi de $69,79 \%$, sendo ainda encontradas 11 propriedades eficientes, ou seja, 64,70\%. Analisando a eficiência de escala, retorno crescente, retorno decrescente e eficiência de escala, obtiveram-se, respectivamente, 23,53; 35,30; e 41,17\% das propriedades, ou seja, quatro trabalharam com eficiência de escala, seis com retornos crescentes e sete com retornos decrescentes.

Nesses três períodos foi calculado o coeficiente de variação (indica a homogeneidade, ou seja, quanto menor o coeficiente de variação, mais semelhantes os produtores), observando-se que: sob a pressuposição de retornos constantes, houve queda do coeficiente de variação na análise dos escores de eficiências, isto é, as propriedades se tornaram mais homogêneas (semelhantes); para retornos variáveis, ocorreu queda do coeficiente de variação entre os dois primeiros períodos e, depois, um pequeno aumento no último período. Na Figura 2, mostram-se as variações dos retornos à escala e da eficiência de escala para os produtores eficientes (17 produtores). 


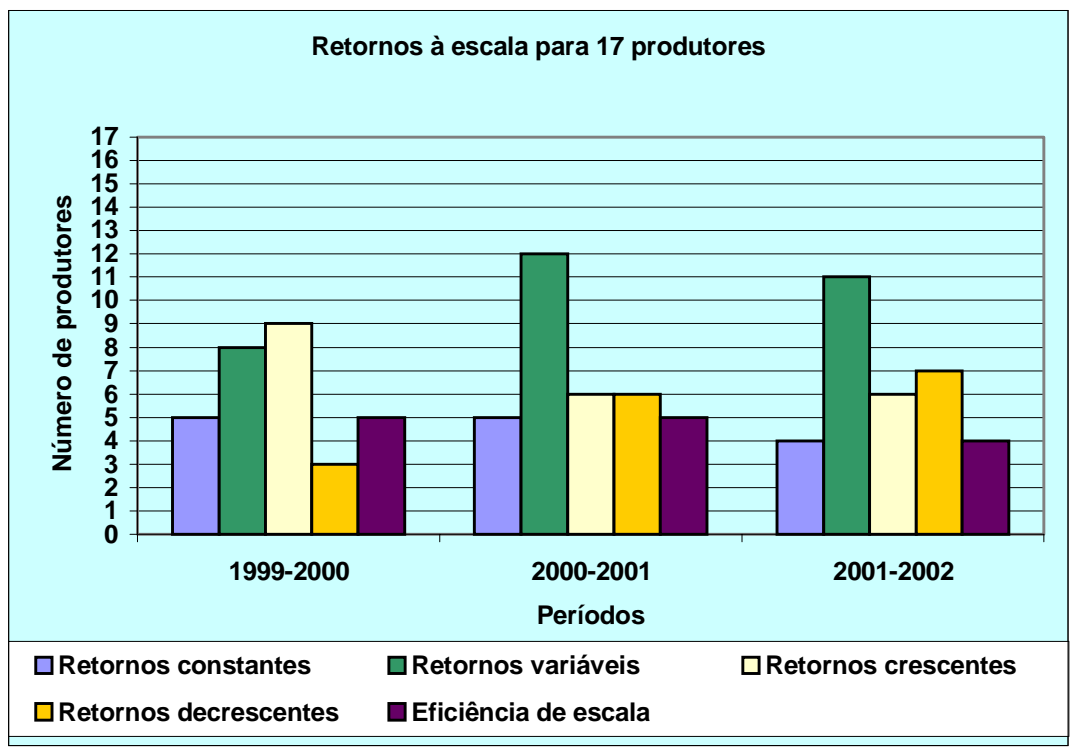

Fonte: dados da pesquisa

Figura 2- Retornos à escala para 17 produtores em três períodos analisados, na Microrregião de Viçosa, MG

Sob a pressuposição de retornos constantes, houve pequena variação nesses três períodos. No período de 1999-2000, cinco eram o número de produtores eficientes, enquanto no período seguinte (2000-2001) permaneceram cinco produtores, e, no último (2001-2002), esse número caiu para quatro produtores eficientes.

Analisando as propriedades sob a pressuposição de retornos variáveis à escala nos três períodos (1999-2000, 2000-2001 e 2001-2002), observou-se a seguinte variação para produtores eficientes: 8,12 e 11, respectivamente.

No tocante à eficiência de escala, observou-se uma queda no número de propriedades com eficiência de escala no terceiro período em relação aos outros dois primeiros, ou seja, de quatro propriedades, enquanto nos outros dois primeiros obtiveram-se cinco propriedades com eficiência de escala. 
Os produtores que trabalharam com retornos crescentes de escala nesses três períodos foram, respectivamente, nove e seis produtores nos dois últimos períodos. Quanto a retornos decrescentes, foram três produtores no primeiro período, subindo para seis no segundo e aumentando para sete em 2001-2002.

\section{Período de novembro/1999 a outubro/2003 (11 propriedades)}

A média de eficiência das 11 propriedades que permaneceram no convênio nesses últimos quatro anos (1999-2003) analisados sob a pressuposição de retornos constantes à escala, no período de 1999-2000, de acordo com a Tabela 4A (Anexo) foi de $82,82 \%$, ou seja, essas propriedades poderiam diminuir suas quantidades de insumos em até $17,18 \%$ e produzir a mesma quantidade de leite ou, de forma alternativa, aumentar sua produção sem usar mais insumos; nesse período, o menor escore de eficiência foi de $35,30 \%$, sendo encontradas quatro propriedades eficientes, ou seja, com escore de eficiência $\theta$ igual a $100 \%$ (36,36\% das propriedades, das 11 consideradas). Sob a pressuposição de retornos variáveis, a média desse período foi de $94,95 \%$, e o menor escore de eficiência, de $46,51 \%$, sendo ainda encontradas seis propriedades eficientes, ou seja, 54,54\%. Analisando a eficiência de escala, retorno crescente, retorno decrescente e eficiência de escala, obtiveram-se, respectivamente, 36,36; 54,54; e 9,10\% das propriedades, ou seja, quatro trabalharam com eficiência de escala, seis com retornos crescentes e um com retornos decrescentes.

Sob a pressuposição de retornos constantes à escala no período de 20002001, conforme a Tabela 5A (Anexo), a média de eficiência foi de 79,91\%; nesse período, o menor escore de eficiência foi de $61,97 \%$, sendo encontradas quatro propriedades eficientes, ou seja, 36,36\%. Na pressuposição de retornos variáveis, a média desse período foi de $88,66 \%$ e o menor escore de eficiência, de $72,85 \%$, sendo ainda encontradas nove propriedades eficientes, ou seja, 81,81\%. Analisando a eficiência de escala, retorno crescente e retorno decrescente, obtiveram-se, respectivamente, 36,$36 ; 27,28$; e 36,36\% das propriedades, ou seja, quatro traba- 
lharam com eficiência de escala, três com retornos crescentes e qautro com retornos decrescentes.

No período de 2001-2002, sob a pressuposição de retornos constantes à escala, conforme a Tabela 6A (Anexo), a média de eficiência foi de $89,62 \%$, ou seja, essas propriedades poderiam diminuir suas quantidades de insumos em até $10,38 \%$ e produzir a mesma quantidade de leite ou, de forma alternativa, aumentar suas produções sem usar mais insumos; nesse período, o menor escore de eficiência foi de $70,62 \%$, ou seja, esse produtor poderia reduzir seus insumos em até $29,38 \%$ ou, de forma alternativa, aumentar sua produção sem usar mais insumos; foram encontradas cinco propriedades eficientes, ou seja, 45,45\%. Sob a pressuposição de retornos variáveis, a média desse período foi de $97,34 \%$ e o menor escore de eficiência, de $85,51 \%$, sendo ainda encontradas oito propriedades eficientes, ou seja, 72,72\%. Analisando a eficiência de escala, retorno crescente, retorno decrescente e eficiência de escala, obtiveram-se, respectivamente, 45,46;27,27; e 27,27\% das propriedades, ou seja, cinco trabalharam com eficiência de escala, três com retornos crescentes e três com retornos decrescentes.

No último período analisado, ou seja, de 2002-2003, sob a pressuposição de retornos constantes à escala, conforme a Tabela 7A (Anexo), a média de eficiência das propriedades foi de $88,49 \%$; nesse período, o menor escore de eficiência foi de $61,45 \%$, sendo encontradas três propriedades eficientes, ou seja, $27,27 \%$. Na pressuposição de retornos variáveis, a média desse período foi de $96,07 \%$ e o menor escore de eficiência, de $72,81 \%$, sendo ainda encontradas oito propriedades eficientes, ou seja, $72,72 \%$. Analisando a eficiência de escala, retorno crescente, retorno decrescente e eficiência de escala, obtiveram-se, respectivamente, 27,28; 36,36 ; e 36,36\% das propriedades, ou seja, três trabalharam com eficiência de escala, quatro com retornos crescentes e quatro com retornos decrescentes.

Foi calculado o coeficiente de variação desses quatro períodos (homogeneidade da amostra). Sob a pressuposição de retornos constantes, houve queda do coeficiente de variação na análise dos escores de 
eficiências entre os três primeiros períodos, havendo, no último, aumento significativo, isto é, as propriedades se tornaram mais homogêneas (semelhantes) nesses três períodos, com a ressalva de que, no último período, ocorreu distanciamento de semelhança entre essas propriedades. No tocante a retornos variáveis, houve queda do coeficiente de variação entre os três primeiros períodos, ou seja, maior semelhança entre as propriedade, e, depois, um pequeno aumento do coeficiente de variação no último período, ou seja, um distanciamento de semelhança das propriedades.

Na Figura 3, observa-se, em retornos constantes de escala, uma variação de uma propriedade que deixou de ser eficiente no período de 20002001 e de duas propriedades no período de 2002-2003.

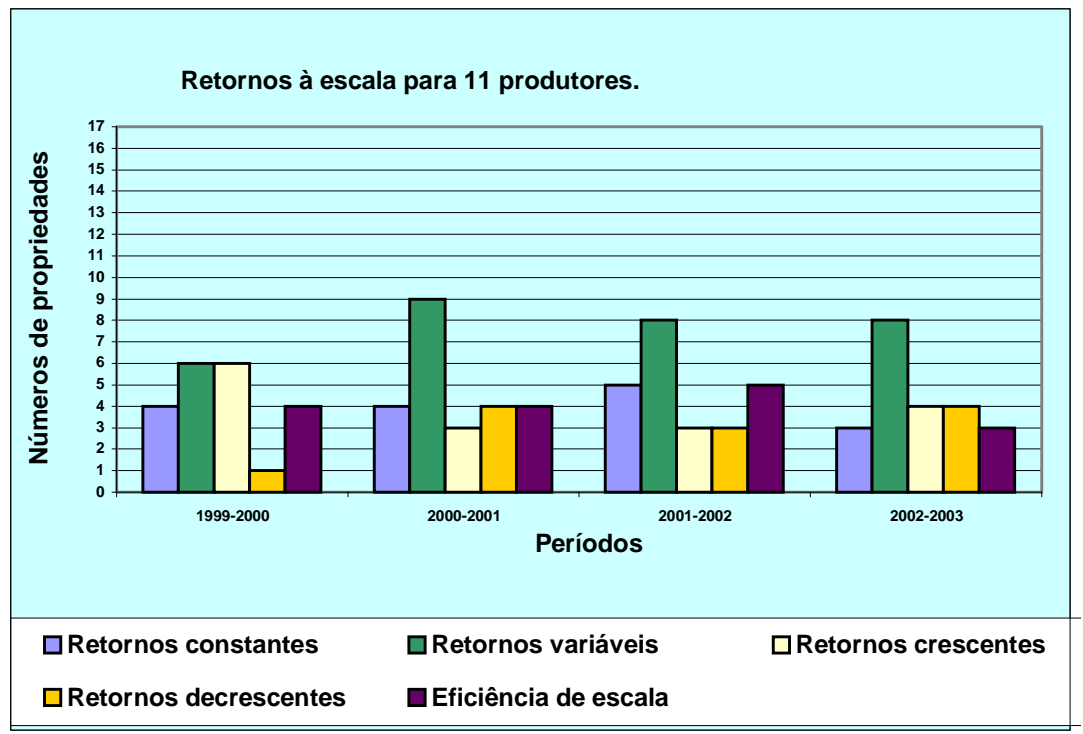

Fonte: dados da pesquisa

Figura 3- Retornos à escala de 11 produtores em quatro períodos analisados, na Microrregião de Viçosa, MG.

Para retornos variáveis, têm-se um aumento do número de propriedades eficientes no período de 1999-2000 a 2000-2001 de quatro produtores e, 
nos dois últimos períodos, diminuição do número de produtores eficientes. Quanto a retornos crescentes à escala do primeiro período para o segundo houve redução de três produtores eficientes, mantendo-se os mesmos números do segundo para o terceiro período, e outra diminuição de duas propriedades que trabalhavam com retornos crescentes à escala.

Analisando retornos decrescentes, observou-se um aumento, no período de 1999-2000 a 2000-2001, de quatro produtores, que, por sua vez, vieram se reduzir nos dois últimos períodos. No tocante à eficiência de escala, houve queda de um produtor eficiente do primeiro para o segundo período e, no terceiro, aumento de um produtor trabalhando eficientemente, enquanto no último período houve redução de dois produtores.

\section{Relação entre eficiência e características das propriedades}

Dos produtores que foram analisados no período de novembro de 1999 a outubro 2002, obtiveram-se os seguintes resultados: analisando sob a pressuposição de retornos constantes, quatro propriedades tiveram evolução de eficiência ao longo dos períodos analisados, com a ressalva de que destes três possuíam alto nível tecnológico e mais da metade das vacas tinha grau de sangue puro (15/16 HZ para cima); três propriedades tiveram queda em eficiência ao longo dos períodos, das quais duas possuíam alto nível tecnológico e mais da metade das vacas tinha grau de sangue puro; apenas uma propriedade teve eficiência estável ao longo desses períodos, com a ressalva de que esta possuía alto nível tecnológico, e mais da metade das vacas possuíam grau de sangue puro.

Sob a pressuposição de retornos variáveis à escala, cinco propriedades tiveram evolução de eficiência no período de 1999 a 2000 para o de 2000 a 2001 e permaneceram estáveis no último período de 2001 a 2002, em que, dessas, quatro possuíam alta tecnologia e duas, com mais da metade das vacas com grau de sangue puro; quatro propriedades, no período de 1999 a 2000 para o de 2000 a 2001, tiveram queda de eficiência. Já, de 2000 a 2001 para o de 2001 a 2002, observou-se evolução de eficiência dessas propriedades, duas com médio grau de tecnologia e duas com mais da metade das vacas com grau de sangue puro. 
Com relação aos produtores analisados nos períodos de novembro de 1999 a outubro 2003, obtiveram-se os seguintes resultados: para retornos constantes, apenas uma propriedade teve evolução de eficiência ao longo de todos os períodos, tendo ela alto nível tecnológico; duas propriedades tiveram queda de eficiência ao longo dos três primeiros períodos (novembro de 1999 a outubro 2002), e no último período (novembro de 2002 a outubro 2003) houve evolução de eficiência, ressaltando-se que elas possuíam alto nível tecnológico, das quais uma tinha mais da metade das vacas com grau de sangue puro; apenas uma propriedade teve eficiência estável ao longo desses períodos e possuía alto nível tecnológico e mais da metade das vacas com grau de sangue de intermediário (entre $3 / 4$ e $15 / 16 \mathrm{HZ}$ ) a puro (15/16 HZ para cima).

Quanto aos retornos variáveis à escala, apenas uma propriedade teve evolução de eficiência em todos os períodos e possuía alto nível tecnológico; apenas uma propriedade, no período de 1999 a 2000 para o de 2000 a 2002, teve queda de eficiência, e de 2001 a 2002 para o de 2002 a 2003 observou-se evolução de eficiência, com essa propriedade possuindo alto grau de tecnologia e mais da metade das vacas com grau de sangue de intermediário a puro.

\section{Conclusões}

Conforme os resultados, verificou-se nos três períodos, que foram de novembro de 1999 a outubro de 2002 (17 propriedades), e nos quatro períodos, que foram de novembro de 1999 a outubro de 2003 (11 propriedades), sob a pressuposição de retornos variáveis, que menos da metade das propriedades trabalhava com ineficiência, ou seja, a maioria era eficiente; enquanto nos retornos constantes à escala a grande maioria das propriedades conveniadas ao PDPL trabalhava com ineficiência de escala, e essa ineficiência aumentou no último período analisado.

Do ponto de vista de recomendações técnicas, as propriedades que eram eficientes, ou seja, as que trabalhavam com eficiência de escala, podem 
ser utilizadas como referência (benchmark) para as ineficientes. Nas propriedades ineficientes, obtiveram-se dois tipos de retornos: nas que trabalhavam com retornos decrescentes, recomenda-se maior atenção dos técnicos na averiguação de "desperdícios" dessas propriedades no uso de recursos e tentar melhorar a condição dos produtores, seja no manejo do rebanho, seja no aumento da relação vacas em lactação/total de vacas, no controle de parasitas ou em qualquer outra variável que influencia diretamente a produção; as propriedades que trabalhavam com retornos crescentes à escala, a produção deve ser estimulada até atingir a eficiência, seja no aumento da área, seja no número de vacas ou em outras variáveis diretamente ligadas ao aumento da produção.

Observou-se que as propriedades, no decorrer dos anos, tornaram-se mais semelhantes, ou seja, aproximaram-se mais das características de eficiência na produção, e isso se deveu, provavelmente, à assistência técnica, com política-padrão para todas as propriedades. Observou-se também, nas propriedades eficientes, que a maioria possuía alta tecnologia e grau de sangue tendendo para puro, mas nem todas que dispunham de alta tecnologia e grau de sangue tendendo para puro eram eficientes, $\mathrm{o}$ que evidencia falha no aproveitamento da tecnologia de produção.

\section{Referências Bibliográficas}

ALVES, E. Medidas de eficiência: métodos não paramétricos. Brasília: Embrapa, 1999. 28 p. (Mimeo).

CARVALHO, L. C. P. Teoria da firma: a produção e a firma. Manual de introdução à economia. Equipe de professores da USP. São Paulo: Saraiva, 1984.

CARVALHO, L. A.; NOVAES, L. P.; MARTINS, C. E.; ZOCCAL, R.; MOREIRA, P.; RIBEIRO, A. C. C. L.; LIMA, V. M. B. Produção de leite. Disponível em: <http://www.epamig.br/programas/ producao_de_leite.htm>. Acesso em: set. 2003. 
CHARNES, A.; COOPER, W. W.; RHODES, E. Measuring the efficiency of decision making units. European Journal of Operational Research, v. 2, n. 6, p. 429-444, 1978.

EMBRAPA. Produção de leite. Disponível em: <http:/ Www.cnpgl.embrapa.br>. Acesso em: set. 2003.

GOMES, A. P. Impactos das transformações da produção de leite no número de produtores e requerimentos de mão-de-obra e capital. Viçosa, MG: UFV, Departamento de Economia Rural, 1999. (Tese de doutorado).

GOMES, S. T. Economia da produção de leite. Belo Horizonte: Ed. Intambé, 2000. 130 p.

IBGE - Instituto Brasileiro de Geografia e Estatística. Censo agropecuário e pesquisa da pecuária municipal - 2003. Disponível em: <http://www. Ibge.gov.br>. Acesso em: set. 2003.

\section{LINS, M. P. E.; MEZA, L. A. Análise envoltória de dados e pers-} pectiva de integração no ambiente de apoio à decisão. Rio de Janeiro: COPPE/UFRJ, 2000.

\footnotetext{
Abstract - This work evaluated the technical efficiency of productive resources utilization in small milk production farmers located in Viçosa region, Minas Gerais, Brazil. The study comprised small milk producers who have received technical assistance from a program created by the Federal University of Viçosa and Nestlé. The technical efficiency was evaluated using the Data Envelopment Analysis (DEA) technique. The results obtained show that there are some farmers efficient and others inefficient. It was also observed that, during the 1999-2003 period, the technical efficiency has improved in the most of the farmers analyzed.
}

Key-words: DEA, technical efficiency, milk production. 


\section{Anexos}

Tabela 1A - Período de novembro de 1999 a outubro de 2000 (17 propriedades)

\begin{tabular}{|c|c|c|c|l|}
\hline \multirow{2}{*}{ Produtor } & Ret. constante & $\begin{array}{c}\text { Ret. não- } \\
\text { crescente }\end{array}$ & Ret. variável & \multirow{2}{*}{ Natureza dos retornos } \\
\cline { 2 - 4 } & $\theta$ & $\theta$ & $\theta$ & \\
\hline 1 & $78,01 \%$ & $78,01 \%$ & $79,14 \%$ & Ret. Crescente \\
\hline 2 & $100,00 \%$ & $100,00 \%$ & $100,00 \%$ & Eficiência de Escala \\
\hline 3 & $92,71 \%$ & $94,75 \%$ & $94,75 \%$ & Ret. Decrescente \\
\hline 4 & $100,00 \%$ & $100,00 \%$ & $100,00 \%$ & Eficiência de Escala \\
\hline 5 & $68,86 \%$ & $68,86 \%$ & $70,68 \%$ & Ret. Crescente \\
\hline 6 & $66,51 \%$ & $66,51 \%$ & $100,00 \%$ & Ret. Crescente \\
\hline 7 & $100,00 \%$ & $100,00 \%$ & $100,00 \%$ & Eficiência de Escala \\
\hline 8 & $35,30 \%$ & $35,30 \%$ & $36,44 \%$ & Ret. Crescente \\
\hline 9 & $66,58 \%$ & $66,58 \%$ & $77,15 \%$ & Ret. Crescente \\
\hline 10 & $100,00 \%$ & $100,00 \%$ & $100,00 \%$ & Eficiência de Escala \\
\hline 11 & $92,78 \%$ & $92,78 \%$ & $100,00 \%$ & Ret. Crescente \\
\hline 12 & $66,29 \%$ & $72,49 \%$ & $72,49 \%$ & Ret. Decrescente \\
\hline 13 & $77,26 \%$ & $77,26 \%$ & $77,57 \%$ & Ret. Crescente \\
\hline 14 & $76,81 \%$ & $90,10 \%$ & $90,10 \%$ & Ret. Decrescente \\
\hline 15 & $67,37 \%$ & $67,37 \%$ & $69,16 \%$ & Ret. Crescente \\
\hline 16 & $100,00 \%$ & $100,00 \%$ & $100,00 \%$ & Eficiência de Escala \\
\hline 17 & $83,49 \%$ & $83,49 \%$ & $100,00 \%$ & Ret. Crescente \\
\hline Média & $80,70 \%$ & & 86,32 & \\
\hline & & & & \\
\hline
\end{tabular}

Fonte: Dados da pesquisa. 
Tabela 2A - Período de novembro de 2000 a outubro de 2001 (17 propriedades)

\begin{tabular}{|c|c|c|c|l|}
\hline \multirow{2}{*}{ Produtor } & Ret. constante & $\begin{array}{c}\text { Ret. não- } \\
\text { crescente }\end{array}$ & Ret. variável & \multirow{2}{*}{ Natureza dos retornos } \\
\cline { 2 - 4 } & $\theta$ & $\theta$ & $\theta$ & \\
\hline 1 & $89,17 \%$ & $100,00 \%$ & $100,00 \%$ & Ret. Decrescente \\
\hline 2 & $100,00 \%$ & $100,00 \%$ & $100,00 \%$ & Eficiência de Escala \\
\hline 3 & $100,00 \%$ & $100,00 \%$ & $100,00 \%$ & Eficiência de Escala \\
\hline 4 & $100,00 \%$ & $100,00 \%$ & $100,00 \%$ & Eficiência de Escala \\
\hline 5 & $78,16 \%$ & $83,93 \%$ & $83,93 \%$ & Ret. Decrescente \\
\hline 6 & $81,90 \%$ & $81,90 \%$ & $100,00 \%$ & Ret. Crescente \\
\hline 7 & $93,86 \%$ & $93,86 \%$ & $97,78 \%$ & Ret. Crescente \\
\hline 8 & $54,17 \%$ & $68,08 \%$ & $68,08 \%$ & Ret. Decrescente \\
\hline 9 & $81,17 \%$ & $81,17 \%$ & $100,00 \%$ & Ret. Crescente \\
\hline 10 & $82,50 \%$ & $82,50 \%$ & $95,18 \%$ & Ret. Crescente \\
\hline 11 & $44,54 \%$ & $44,54 \%$ & $100,00 \%$ & Ret. Crescente \\
\hline 12 & $98,85 \%$ & $100,00 \%$ & $100,00 \%$ & Ret. Decrescente \\
\hline 13 & $100,00 \%$ & $100,00 \%$ & $100,00 \%$ & Eficiência de Escala \\
\hline 14 & $84,91 \%$ & $100,00 \%$ & $100,00 \%$ & Ret. Decrescente \\
\hline 15 & $79,57 \%$ & $84,51 \%$ & $84,51 \%$ & Ret. Decrescente \\
\hline 16 & $100,00 \%$ & $100,00 \%$ & $100,00 \%$ & Eficiência de Escala \\
\hline 17 & $73.75 \%$ & $73.75 \%$ & $100 \%$ & Ret. Crescente \\
\hline Média & $84,86 \%$ & & $95,85 \%$ & \\
\hline
\end{tabular}

Fonte: Dados da pesquisa. 
Tabela 3A - Período de novembro de 2001 a outubro de 2002 (17 propriedades)

\begin{tabular}{|c|c|c|c|l|}
\hline \multirow{2}{*}{ Produtores } & Ret. constante & $\begin{array}{c}\text { Ret. não- } \\
\text { crescente }\end{array}$ & Ret. variável & \multirow{2}{*}{ Natureza dos retornos } \\
\cline { 2 - 4 } & $\theta$ & $\theta$ & $\theta$ & \\
\hline 1 & $100,00 \%$ & $100,00 \%$ & $100,00 \%$ & Eficiência de Escala \\
\hline 2 & $74,17 \%$ & $94,52 \%$ & $94,52 \%$ & Ret. Decrescente \\
\hline 3 & $100,00 \%$ & $100,00 \%$ & $100,00 \%$ & Eficiência de Escala \\
\hline 4 & $100,00 \%$ & $100,00 \%$ & $100,00 \%$ & Eficiência de Escala \\
\hline 5 & $74,41 \%$ & $100,00 \%$ & $100,00 \%$ & Ret. Decrescente \\
\hline 6 & $78,70 \%$ & $78,70 \%$ & $100,00 \%$ & Ret. Crescente \\
\hline 7 & $76,60 \%$ & $76,60 \%$ & $78,35 \%$ & Ret. Crescente \\
\hline 8 & $76,27 \%$ & $95,40 \%$ & $95,40 \%$ & Ret. Decrescente \\
\hline 9 & $63,57 \%$ & $63,57 \%$ & $76,14 \%$ & Ret. Crescente \\
\hline 10 & $76,56 \%$ & $76,56 \%$ & $100,00 \%$ & Ret. Crescente \\
\hline 11 & $92,40 \%$ & $92,40 \%$ & $100,00 \%$ & Ret. Crescente \\
\hline 12 & $87,87 \%$ & $100,00 \%$ & $100,00 \%$ & Ret. Decrescente \\
\hline 13 & $100,00 \%$ & $100,00 \%$ & $100,00 \%$ & Eficiência de Escala \\
\hline 14 & $62,21 \%$ & $69,79 \%$ & $69,79 \%$ & Ret. Decrescente \\
\hline 15 & $99,73 \%$ & $100,00 \%$ & $100,00 \%$ & Ret. Decrescente \\
\hline 16 & $97,54 \%$ & $100,00 \%$ & $100,00 \%$ & Ret. Decrescente \\
\hline 17 & $69,01 \%$ & $69,01 \%$ & $82,56 \%$ & Ret. Crescente \\
\hline Média & $84,06 \%$ & & $93,93 \%$ & \\
\hline
\end{tabular}

Fonte: Dados da pesquisa. 
Tabela 4A - Período de novembro de 1999 a outubro de 2000 (11 propriedades)

\begin{tabular}{|c|c|c|c|l|}
\hline \multirow{2}{*}{ Produtor } & Ret. constante & $\begin{array}{c}\text { Ret. não- } \\
\text { crescente }\end{array}$ & Ret. variável & \multirow{2}{*}{ Natureza dos retornos } \\
\cline { 2 - 4 } & $\theta$ & $\theta$ & $\theta$ & \\
\hline 1 & $78,01 \%$ & $78,01 \%$ & $82,04 \%$ & Ret. Crescente \\
\hline 2 & $100,00 \%$ & $100,00 \%$ & $100,00 \%$ & Eficiência de Escala \\
\hline 3 & $97,46 \%$ & $97,46 \%$ & $100,00 \%$ & Ret. Crescente \\
\hline 4 & $100,00 \%$ & $100,00 \%$ & $100,00 \%$ & Eficiência de Escala \\
\hline 5 & $68,86 \%$ & $68,86 \%$ & $83,33 \%$ & Ret. Crescente \\
\hline 6 & $66,51 \%$ & $66,51 \%$ & $90,91 \%$ & Ret. Crescente \\
\hline 7 & $100,00 \%$ & $100,00 \%$ & $100,00 \%$ & Eficiência de Escala \\
\hline 8 & $35,30 \%$ & $35,30 \%$ & $46,51 \%$ & Ret. Crescente \\
\hline 9 & $66,58 \%$ & $66,58 \%$ & $100,00 \%$ & Ret. Crescente \\
\hline 10 & $66,29 \%$ & $72,49 \%$ & $72,49 \%$ & Ret. Decrescente \\
\hline 11 & $100,00 \%$ & $100,00 \%$ & $100,00 \%$ & Eficiência de Escala \\
\hline Média & $82,82 \%$ & & $94,95 \%$ & \\
\hline
\end{tabular}

Fonte: Dados da pesquisa.

Tabela 5A - Período de novembro de 2000 a outubro de 2001 (11 propriedades)

\begin{tabular}{|c|c|c|c|l|}
\hline \multirow{2}{*}{ Produtor } & Ret. constante & $\begin{array}{c}\text { Ret. não- } \\
\text { crescente }\end{array}$ & Ret. variável & \multirow{2}{*}{ Natureza dos retornos } \\
\cline { 2 - 4 } & $\theta$ & $\theta$ & $\theta$ & \\
\hline 1 & $91,74 \%$ & $100,00 \%$ & $100,00 \%$ & Ret. Decrescente \\
\hline 2 & $99,69 \%$ & $100,00 \%$ & $100,00 \%$ & Ret. Decrescente \\
\hline 3 & $100,00 \%$ & $100,00 \%$ & $100,00 \%$ & Eficiência de Escala \\
\hline 4 & $100,00 \%$ & $100,00 \%$ & $100,00 \%$ & Eficiência de Escala \\
\hline 5 & $76,22 \%$ & $100,00 \%$ & $100,00 \%$ & Ret. Decrescente \\
\hline 6 & $79,77 \%$ & $79,77 \%$ & $100,00 \%$ & Ret. Crescente \\
\hline 7 & $93,83 \%$ & $93,83 \%$ & $97,92 \%$ & Ret. Crescente \\
\hline 8 & $61,97 \%$ & $72,85 \%$ & $72,85 \%$ & Ret. Decrescente \\
\hline 9 & $82,65 \%$ & $82,65 \%$ & $100,00 \%$ & Ret. Crescente \\
\hline 10 & $100,00 \%$ & $100,00 \%$ & $100,00 \%$ & Eficiência de Escala \\
\hline 11 & $100,00 \%$ & $100,00 \%$ & $100,00 \%$ & Eficiência de Escala \\
\hline Média & $79,91 \%$ & & $88,66 \%$ & \\
\hline
\end{tabular}

Fonte: Dados da pesquisa. 
Tabela 6A - Período de novembro de 2001 a outubro de 2002 (11 propriedades)

\begin{tabular}{|c|c|c|c|l|}
\hline \multirow{2}{*}{ Produtor } & Ret. constante & Ret. não-crescente & Ret. variável & \multirow{2}{*}{ Natureza dos retornos } \\
\cline { 2 - 4 } & $\theta$ & $\theta$ & $\theta$ & \\
\hline 1 & $100,00 \%$ & $100,00 \%$ & $100,00 \%$ & Eficiência de Escala \\
\hline 2 & $72,07 \%$ & $75,91 \%$ & $75,91 \%$ & Ret. Decrescente \\
\hline 3 & $100,00 \%$ & $100,00 \%$ & $100,00 \%$ & Eficiência de Escala \\
\hline 4 & $100,00 \%$ & $100,00 \%$ & $100,00 \%$ & Eficiência de Escala \\
\hline 5 & $100,00 \%$ & $100,00 \%$ & $100,00 \%$ & Eficiência de Escala \\
\hline 6 & $74,23 \%$ & $74,23 \%$ & $100,00 \%$ & Ret. Crescente \\
\hline 7 & $79,56 \%$ & $79,56 \%$ & $85,51 \%$ & Ret. Crescente \\
\hline 8 & $84,89 \%$ & $95,40 \%$ & $95,40 \%$ & Ret. Decrescente \\
\hline 9 & $70,62 \%$ & $70,62 \%$ & $100,00 \%$ & Ret. Crescente \\
\hline 10 & $92,00 \%$ & $100,00 \%$ & $100,00 \%$ & Ret. Decrescente \\
\hline 11 & $100,00 \%$ & $100,00 \%$ & $100,00 \%$ & Eficiência de Escala \\
\hline Média & $89,62 \%$ & & $97,34 \%$ & \\
\hline
\end{tabular}

Fonte: Dados da pesquisa.

Tabela 7A - Período de novembro de 2002 a outubro de 2003 (11 propriedades)

\begin{tabular}{|c|c|c|c|l|}
\hline \multirow{2}{*}{ Produtor } & Ret. constante & $\begin{array}{c}\text { Ret. não- } \\
\text { crescente }\end{array}$ & Ret. variável & \multirow{2}{*}{ Natureza dos retornos } \\
\cline { 2 - 4 } & $\theta$ & $\theta$ & $\theta$ & \\
\hline 1 & $66,47 \%$ & $72,81 \%$ & $72,81 \%$ & Ret. Decrescente \\
\hline 2 & $89,09 \%$ & $100,00 \%$ & $100,00 \%$ & Ret. Decrescente \\
\hline 3 & $100,00 \%$ & $100,00 \%$ & $100,00 \%$ & Eficiência de Escala \\
\hline 4 & $67,31 \%$ & $67,31 \%$ & $79,08 \%$ & Ret. Crescente \\
\hline 5 & $100,00 \%$ & $100,00 \%$ & $100,00 \%$ & Eficiência de Escala \\
\hline 6 & $61,45 \%$ & $61,45 \%$ & $100,00 \%$ & Ret. Crescente \\
\hline 7 & $96,68 \%$ & $96,68 \%$ & $100,00 \%$ & Ret. Crescente \\
\hline 8 & $89,81 \%$ & $100,00 \%$ & $100,00 \%$ & Ret. Decrescente \\
\hline 9 & $67,48 \%$ & $67,48 \%$ & $100,00 \%$ & Ret. Crescente \\
\hline 10 & $72,76 \%$ & $92,52 \%$ & $92,52 \%$ & Ret. Decrescente \\
\hline 11 & $100,00 \%$ & $100,00 \%$ & $100,00 \%$ & Eficiência de Escala \\
\hline Média & $88,49 \%$ & & $96,07 \%$ & \\
\hline
\end{tabular}

Fonte: Dados da pesquisa. 